\title{
Carbapenem resistance in Acinetobacter baumannii: the molecular epidemic features of an emerging problem in health care facilities
}

\author{
Raffaele Zarrilli ${ }^{1,2}$, Maria Giannouli ${ }^{1}$, Federica Tomasone ${ }^{1}$, Maria Triassi ${ }^{1}$, and Athanassios \\ Tsakris $^{3}$ \\ ${ }^{1}$ Department of Preventive Medical Sciences, Hygiene Section, University of Naples 'Federico II', Naples, Italy \\ 2 CEINGE Advanced Biotechnologies, Naples, Italy \\ ${ }^{3}$ Department of Microbiology, Medical School, University of Athens, Athens, Greece
}

\begin{abstract}
Acinetobacter baumannii is an opportunistic gram-negative pathogen with increasing relevance in a variety of nosocomial infections especially among intensive-care-unit (ICU) patients. Carbapenems have been widely used to treat serious multidrug-resistant $A$. baumannii infections; however, incidences of carbapenem-resistant $A$. baumannii are rising in several parts of the world and large and sustained outbreaks caused by such bacteria have been described. Carbapenem-resistant A. baumannii epidemics are sustained by clusters of highly similar strains that successfully spread among different cities and countries; their resistance phenotype is mainly due to the acquisition of carbapenem-hydrolyzing class D $\beta$-lactamase (CHDL) genes flanked by insertion sequence (IS) elements. Multi-facility outbreaks can be also sustained by inter-hospital transfer of colonized patients. Here, we review the global epidemiology of carbapenem-resistant $A$. baumannii, with the emphasis on the molecular epidemiology and genetic characterization of carbapenem resistance in epidemic strains.
\end{abstract}

Key words: Acinetobacter baumannii, nosocomial outbreaks, genotyping, carbapenemases

J Infect Dev Ctries 2009; 3(5):335-341.

Received 25 March 2009 - Accepted 17 May 2009

Copyright () 2009 Zarrilli et al. This is an open-access article distributed under the Creative Commons Attribution License, which permits unrestricted use, distribution, and reproduction in any medium, provided the original work is properly cited.

\section{Introduction}

Acinetobacter spp. are glucose-non fermentative gram-negative coccobacilli that have emerged in recent years as a cause of healthcare-associated infections [1,2]. Considered to be commensals of low-grade pathogenicity, i.e. opportunistic microorganisms, Acinetobacter were frequently ignored in the 1970s whenever isolated from clinical specimens [1]. The genus Acinetobacter currently contains up to 32 described named and unnamed (genomic) species [1]. Acinetobacter baumannii, genomic species 3 and 13TU, three of the most clinically relevant species, are genetically and phenotypically very similar to an environmental species, A. calcoaceticus, and are therefore grouped together into the so-called A. calcoaceticus-A. baumannii (Acb) complex [1]. Because phenotypic identification of Acinetobacter isolates to the species level has proven to be insufficient, several genotypic methods have been developed for genomic species identification, that include amplified 16S rRNA gene restriction analysis (ARDRA), high-resolution fingerprint analysis by amplified fragment length polymorphism (AFLP), or sequence analysis of the 16S-23S rRNA gene spacer region $[1,3,4]$. However, genotypic methods for species identification are often unavailable in developing countries, where Acinetobacter are frequently isolated but identified only at genus level. The species that is most commonly involved in hospital infections is $A$. baumannii, which causes a variety of health-care associated infections, comprising bacteremia, urinary tract infection, surgical-site infection, and nosocomial and ventilator-associated pneumonia, especially in intensive-care-unit (ICU) patients [1,2,5-7]. The rates of recovery of $A$. baumannii from natural environments and its incidence in the community are low, while its rate of carriage by hospitalized patients is high and its occurrence in the hospital setting is frequent [1]. A. baumannii has simple growth requirements and can survive in dry conditions. This might contribute to the fitness of A. baumannii in the hospital environment, which represents the main reservoir of the bacterium [1]. 


\section{Carbapenem resistance mechanisms in $A$. baumannii}

Resistance to antimicrobial agents may be the main advantage of $A$. baumannii in the nosocomial environment. Multidrug-resistant isolates of $A$. baumannii have been reported increasingly during the last decade, probably as a consequence of extensive use of antimicrobial agents in western countries [2,8]. Also, as recently demonstrated by a retrospective, matched cohort study, patients with infection by multidrug-resistant Acinetobacter show higher mortality rate and length of hospitalization than patients with infection by susceptible Acinetobacter [5].

Mounting evidence indicates that A. baumannii possesses a broad range of mechanisms of resistance to all existing antibiotic classes as well as a prodigious capacity to acquire new determinants of resistance $[1,2]$ Genome sequence analysis of six $A$. baumannii clinical strains has shown the presence of a resistance island with a variable composition of resistance genes interspersed with transposons, integrons, and other mobile genetic elements in three of them [9-11]. Also, plasmids carrying resistance genes and/or resistance determinants involved in horizontal gene transfer have been described in several A. baumannii strains [12-19].

The broad-spectrum $\beta$-lactam antibiotics, carbapenems, were introduced by 1985 and have been for years the most important agents for the treatment of infections caused by multidrug-resistant A. baumannii. Carbapenem resistance in Acinetobacter is now observed increasingly worldwide, and constitutes a sentinel event for emerging antimicrobial resistance $[2,12]$. Carbapenem-resistant isolates of A. baumannii are usually resistant to all classes of antimicrobials, and show intermediate resistance to rifampin, while usually retaining susceptibility to tigecycline and colistin $[2,12,20]$. Resistance against carbapenems is, in itself, considered sufficient to define an isolate of A. baumannii as highly resistant [12]. The resistance of $A$. baumannii to carbapenems can be mediated by one of the resistance mechanisms that are known to occur in bacteria, including enzymatic inactivation, active efflux of drugs, and modification of target sites (Table 1). The production of carbapenem-hydrolizing beta-lactamases is the most common mechanism responsible for carbapenem resistance in $A$. baumannii. Several carbapenem-hydrolyzing $\beta$ lactamases have been identified so far in $A$. baumannii. These include metallo- $\beta$-lactamases
(VIM-, IMP- and SIM-types), which have been sporadically reported in some parts of the world and have been associated with class 1 integrons $[2,7,12]$. Nevertheless, the most widespread carbapenemases in A. baumannii are class $\mathrm{D} \beta$-lactamases. Three main acquired carbapenem-hydrolysing class D oxacillinase (CHDL) gene clusters have been identified either in the chromosome or in plasmids of A. baumannii strains, represented by the bla $a_{\mathrm{OXA}-23^{-}}$, $b l a_{\mathrm{OXA}-24 / 40^{-}}$, and $b l a_{\mathrm{OXA}-58^{-}}$-like genes [12]. Different insertion sequence (IS) elements at the $5^{\prime}$ and/or the 3' end of $b l a_{\mathrm{OXA}-23^{-}}$, and $b l a_{\mathrm{OXA}-58^{-}}$-like genes, such as ISAbal, ISAba2, ISAba3, or IS18, have been demonstrated to regulate their expression $[12,13,15-$ 17]. Also, it has been recently demonstrated that the ISAbal element is capable of transposition in E. coli and of mobilizing an antibiotic resistance gene [18]. In addition to these CHDL genes, the chromosomal bla $_{\text {OXA-51-like }}$ gene, intrinsic to A. baumannii species, has been demonstrated to confer carbapenem resistance when an ISAbal element is inserted upstream of the gene [19]. Reduced susceptibility to carbapenems has also been associated with the modification of penicillin-binding proteins and porins or with upregulation of the AdeABC efflux system, and it has been suggested that the interplay of different mechanisms might result in high-level carbapenem resistance in A. baumannii (Table 1) [2123].

\section{Global epidemiology of carbapenem- resistant Acinetobacter baumannii}

Carbapenem resistance in $A$. baumannii is now an emerging issue worldwide [2]. Surveillance studies indicate that the percentage of carbapenemresistant isolates gradually increased over the last ten years in Europe, North America, and Latin America [2]. Numerous outbreaks of carbapenem-resistant $A$. baumannii were reported from hospitals in Northern Europe (Spain, Portugal, France, the United Kingdom (UK), the Netherlands, Czech Republic, Poland) [1,2, 24-29], Southern Europe and the Middle East (Bulgaria, Greece, Italy, Turkey, Lebanon, Israel, Iran, Iraq and United Arab Emirates) [2,68,10,12,14,16,17,30-35], North America and Latin America (Argentina, Brazil, Chile and Colombia) [2,36,37], Tunisia and South Africa [38,39], China, Taiwan, Singapore, Hong Kong, Japan, South Korea [2,40,41], and Australia [42] and from areas as remote as French Polynesia [43]. In the majority of cases, one or two epidemic strains were detected in a given hospital. Transmission of such strains was 
Table 1. Carbapenem resistance mechanisms in A. baumannii.

\begin{tabular}{|c|c|c|}
\hline $\begin{array}{l}\text { Mechanism or } \\
\text { responsible structure }\end{array}$ & Note & References \\
\hline \multicolumn{3}{|l|}{$\beta$-lactam hydrolysis } \\
\hline $\begin{array}{l}\text { IMP-1, }-2,-4,-5,-6,-11 \\
\text { VIM-2, SIM-1 }\end{array}$ & $\begin{array}{l}\text { Class B metallo beta-lactamases. Class } 1 \text { integron- } \\
\text { associated genes. }\end{array}$ & 2,12 \\
\hline OXA-23 cluster & $\begin{array}{l}\text { Class D beta-lactamases. Chromosomal or plasmid genes } \\
\text { flanked by IS elements. }\end{array}$ & $2,12,13,17$ \\
\hline OXA-24/40 cluster & Class D beta-lactamases. Chromosomal or plasmid genes. & 2,12 \\
\hline OXA-58 cluster & $\begin{array}{l}\text { Class D beta-lactamases. Plasmid or chromosomal genes } \\
\text { flanked by IS elements. }\end{array}$ & $12-16$ \\
\hline OXA-51cluster & $\begin{array}{l}\text { Chromosomal class D beta-lactamase intrinsic to } A \text {. } \\
\text { baumannii. Confers carbapenem resistances if IS elements } \\
\text { are inserted upstream of the gene }\end{array}$ & 2,19 \\
\hline \multicolumn{3}{|c|}{$\begin{array}{c}\text { Changes in outer-membrane proteins } \\
\text { (OMPs) }\end{array}$} \\
\hline $\mathrm{CarO}$ & $26 \mathrm{kDa}$ OMP implicated in drug influx & 21 \\
\hline 33 to $36-\mathrm{kDa}$ OMP & Other OMPs associated with carbapenem resistance & 2,12 \\
\hline \multicolumn{3}{|l|}{ OprD-like OMP } \\
\hline \multicolumn{3}{|l|}{ Target alteration } \\
\hline Altered penicillin-binding proteins & Reduced PBP-2 expression & 22 \\
\hline
\end{tabular}

observed between hospitals in the same city and also on a national scale [1,2,6,12,2427,29,30,3,38,42,44-46] and a direct epidemiological link was established in several cases $[6,25,28,29,38,42,44-46]$. The inter-hospital transfer of colonised patients was demonstrated during multifacility outbreaks that occurred in the Netherlands [25], Italy [6], South Africa [38], and Tunisia [39]. The international transfer of patients colonised by carbapenem-resistant $A$. baumannii was also reported [28, 29, 42]. More recently, several cases of United Kingdom and US military and nonmilitary personnel returning from operations in Iraq and Afghanistan and harbouring infections caused by carbapenemresistant A. baumannii were reported [44-46] (Figure $1)$.

Outbreaks caused by carbapenem-resistant $A$. baumannii have also been observed in developing countries such as Morocco, Thailand, India, and Indonesia $[47,41]$. Furthermore, infections caused by Acinetobacter spp. without specifying whether they are caused by carbapenem-resistant strains have been reported in Africa (Lagos, Nigeria) and several Asian countries including Nepal [48-50].

\section{Molecular epidemiology of carbapenem- resistant Acinetobacter baumannii}

Genotypic characterization of carbapenemresistant $A$. baumannii strains showed the occurrence of $b l a_{\text {OXA-23- }}, b l a_{\text {OXA-24/40- }}$, or $b l a_{\text {OXA-58 }}$-like genes in multiple isolates from the same hospital or among different hospitals worldwide [2,12,13,33,34,43,52]. bla $a_{\text {OXA-23 }}$ was mostly detected in isolates from Asian countries [41], but was also reported in South America [36,37] and Europe [12,17,31,51]; bla $a_{\text {OXA-58 }}$ was frequently found in Europe [6,7,10,14,30,33,16,30-35,51]. bla $a_{\mathrm{OXA}-24 / 40}$ was mostly found in the Iberian peninsula and Asia, but also detected in Iran, Belgium, Czech Republic and the United States of America (USA) [2,26,27,41,44,51,52] (Figure 1). Molecular epidemiology of $A$. baumannii strains responsible for outbreaks that occurred in several European hospitals revealed clusters of highly similar strains, which were defined as European clones I and II $[1,2]$ and corresponded to sequence type (ST) groups 2 and 1, respectively, identified by sequence-based typing [53]. A recent study on a collection of 96 carbapenem-resistant A. baumannii strains collected in 17 European countries assigned $85 \%$ of them to sequence type (ST) groups 1 and 2 by multiple PCRs [51]. The prevalence of carbapenem-resistant epidemic A. baumannii strains belonging to ST group 1 was also demonstrated in Italy and Greece $[30,33]$ along with the spread of a prevalent clone isolated with identical pulsed field gel electrophoresis (PFGE) profiles in two hospitals in Naples, Italy, and in three hospitals in three distinct Greek cities [33]. The circulation of distinct carbapenem-resistant $A$. 
Figure 1

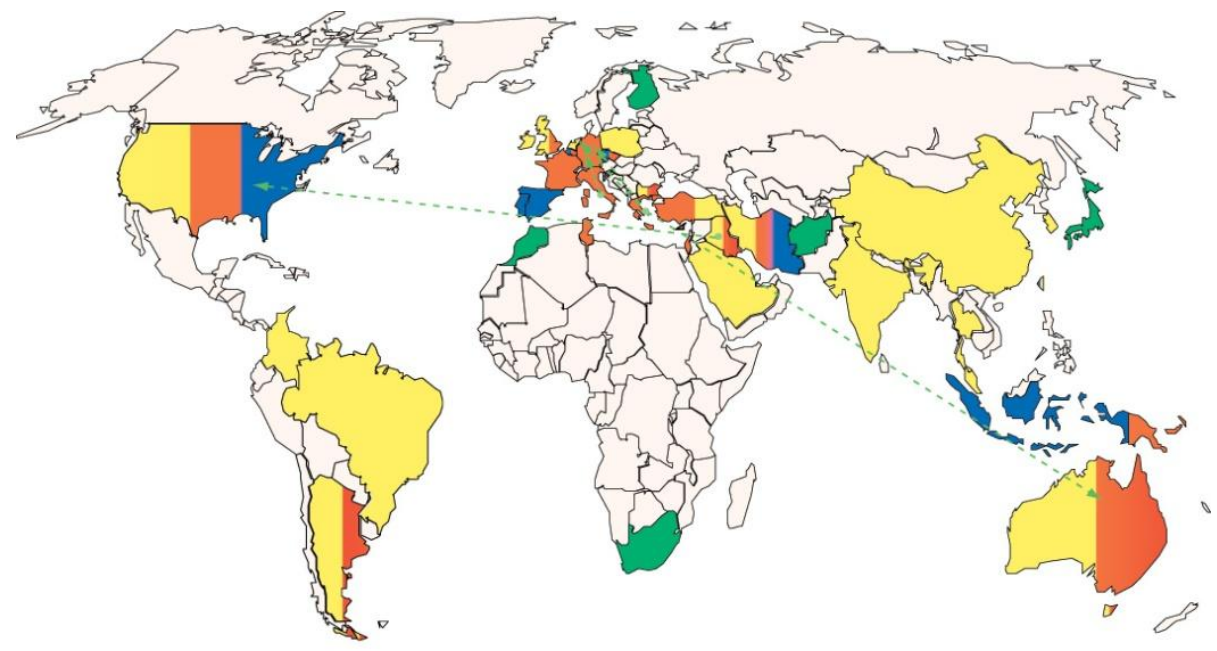

Geographic distribution and genetic charactefízation of carbapenem-resistant A. baumannii. Countries reporting carbapenem-resistant $A$. baumannii outbreaks producing OXA-23-, OXA-24/40-, and/or OXA-58-type enzymes are indicated by yellow, blue, and red colours, respectively. Countries reporting carbapenem-resistant $A$. baumannii outbreaks in which the OXA-type enzyme has not been identified are indicated by green colour. Green arrows indicate hospital transfer of colonized/infected patients by carbapenem-resistant $A$. baumannii between different countries.

baumannii genotypes belonging to ST group 2 in Greece and in Lebanon, and to two novel ST groups 4 and 5 in different Greek and Turkish cities, was also shown in the same study [33]. The $b l a_{\text {OXA-58 }}$ gene flanked by IS elements was present in all carbapenem-resistant genotypes analyzed from hospitals in Greece, Italy, Lebanon, and Turkey [7,16,33] (Figure 1). Of note, each of the IS elements flanking the 5' end of bla ${ }_{\text {OXA-58 }}$ occurred in strains of distinct ST groups and PFGE profiles isolated in the same geographic region. Thus, ISAba2 element was detected in Greece and Italy, IS 18 in Lebanon and Turkey, and ISAbal in Turkey and Italy, suggesting that they might have been acquired through horizontal gene transfer [33]. In further support of this hypothesis, plasmid-borne bla $a_{\text {OXA-58 }}$ has been found in the majority of carbapenem-resistant $A$. baumannii strains isolated in Europe $[6,7,10,13,14,16,33]$. The spread of carbapenemresistant $A$. baumannii carrying the $b l a_{\text {OXA-58 }}$ gene might had also been contributed by international transfer of colonised patients, as recently demonstrated from Greece to Belgium [28], Greece to Australia [42], and Iraq to USA military services [44] (Figure 1).

\section{Conclusions}

Outbreaks of carbapenem-resistant A. baumannii are increasingly reported in several parts of the world that also include developing countries. They are sustained by clusters of highly similar strains that successfully spread among different cities and countries and are selected because of the acquisition of CHDLs genes flanked by IS elements. Multifacility A. baumannii outbreaks can be also sustained by inter-hospital transfer of colonized patients. This emphasizes the need to adopt surveillance and infection control programmes to prevent colonisation and infection by multidrug-resistant $A$. baumannii in the hospital setting. These programmes would include the study of global epidemiology of multidrug-resistant $A$. baumannii using molecular typing of bacterial isolates and characterization of antibiotic resistance in order to control the spread of A. baumannii infections over a wide geographic region.

\section{Acknowledgments}

Work performed in the authors' laboratories is supported in part by a grant from Agenzia Italiana del Farmaco (AIFA2007 contract no. FARM7X9F8K). Restriction placed on the number of references that could be cited in this review mean that, in many cases, either a single paper or a review is cited. We apologize to those authors whose work has not been cited.

\section{References}

1. Dijkshoorn L, Nemec A, Seifert H (2007) An increasing threat in hospitals: multidrugresistant Acinetobacter baumannii. Nat Rev Microbiol 5: 939-51.

2. Peleg AY, Seifert H, Paterson DL (2008) Acinetobacter baumannii: emergence of a successful pathogen. Clin Microbiol Rev 21: 538-582. 
3. Dijkshoorn L, van Harsselaar B, Tjernberg I, Bouvet PJ, Vaneechoutte M (1998) Evaluation of amplified ribosomal DNA restriction analysis for identification of Acinetobacter genomic species. Syst Appl Microbiol 21: 33-39.

4. Chang HC, Wei YF, Dijkshoorn L, Vaneechoutte M, Tang CT, Chang TC (2005) Species-level identification of isolates of the Acinetobacter calcoaceticus-Acinetobacter baumannii complex by sequence analysis of the 16S-23S rRNA gene spacer region. J Clin Microbiol 43: 1632-1639.

5. Sunenshine RH, Wright M-O, Maragakis LL, Haris AD, Song X, Hebden J, Cosgrove SE, Anderson A, Carnell J, Jernigan DB, Kleinbaum DG, Perl TM, Standiford HC, Srinivasan A (2007) Multidrug-resistant Acinetobacter infection mortality rate and length of hospitalization. Emerg Infect Dis 13: 97-103.

6. Zarrilli R, Casillo R, Di Popolo A, Tripodi MF, Bagattini M, Cuccurullo S, Crivaro V, Ragone E, Mattei A, Galdieri N, Triassi M, Utili R (2007) Molecular epidemiology of a clonal outbreak of multidrug-resistant Acinetobacter baumannii in a university hospital in Italy. Clin Microbiol Infect 13: 481-489.

7. Tsakris A, Ikonomidis A, Poulou A, Spanakis N, Vrizas D, Diomidous M, Pournaras S, Markou F (2008) Clusters of imipenem-resistant Acinetobacter baumannii clones producing different carbapenemases in an intensive care unit. Clin Microbiol Infect 14: 588-594.

8. Zarrilli R, Crispino M, Bagattini M, Barretta E, Di Popolo A, Triassi M, Villari P (2004) Molecular epidemiology of sequential outbreaks of Acinetobacter baumannii in an intensive care unit shows the emergence of carbapenem resistance. J Clin Microbiol 42: 946-953.

9. Vallenet D, Nordmann P, Barbe V, Poirel L, Mangenot S, Bataille E, Dossat C, Gas S, Kreimeyer A, Lenoble P, Oztas S, Poulain J, Segurens B, Robert C, Abergel C, Claverie JM, Raoult D, Médigue C, Weissenbach J, Cruveiller S (2005)

Comparative analysis of Acinetobacters: three genomes for three lifestyles. PLos ONE 3: e1805.

10. Iacono M., Villa L, Fortini D, Bordoni R, Imperi F, Bonnal RJ, Sicheritz-Ponten T, De Bellis G, Visca P, Cassone A, Carattoli A (2008) Whole genome pyrosequencing of an epidemic multidrug resistant Acinetobacter baumannii of the European clone II. Antimicrob Agents Chemother 52: 2616-2625.

11. Adams MA, Goglin K, Molyneaux N, Hujer KM, Lavender H, Jamison JJ, MacDonald IJ, Martin KM, Russo T, Campagnari AA, Hujer AM, Bonomo RA, Gill SR (2009) Comparative genome sequence analysis of multidrug-resistant Acinetobacter baumannii. J Bacteriol 190: 8053-8064.

12. Poirel L, Nordmann P (2006) Carbapenem resistance in Acinetobacter baumannii: mechanisms and epidemiology. Clin Microbiol Infect 12: 826-836.

13. Poirel L, Nordmann P (2006) Genetic structure at the origin of acquisition and expression of the carbapenemhydrolyzing oxacillinase gene bla $_{\text {OXA-58 }}$ in Acinetobacter baumannii. Antimicrob Agents Chemother 50: 1442-1448.

14. Pournaras S, Markogiannakis A, Ikonomidis A, Kondyli L, Bethimouti K, Maniatis AN, Legakis NJ, Tsakris A (2006) Outbreak of multiple clones of imipenem resistant Acinetobacter baumannii isolates expressing OXA-58 carbapenemase in an intensive care unit. J Antimicrob Chemother 57: 557-561.

15. Chen T-L, Wu RC-C, Shaio M-F, Fung C-P, Cho W-L (2008) Acquisition of a plasmid-borne blaOXA-58 gene with an upstream IS1008 insertion conferring a high level of carbapenem resistance to Acinetobacter baumannii. Antimicrob Agents Chemother 52: 2573-2580.

16. Zarrilli R, Vitale D, Di Popolo A, Bagattini M, Daoud Z, Khan AU, Afif C, Triassi M (2008) A plasmid-borne $b l a_{\text {OXA-58 }}$ gene confers imipenem resistance to Acinetobacter baumannii isolates from a Lebanese hospital. Antimicrob Agents Chemother 52: 4115-4120.

17. Meric M, Kasap M, Gacar G, Budak F, Dundar D, Kolayli F, Eroglu C, Vahaboglu H (2008) Emergence and spread of carbapenem-resistant Acinetobacter baumannii in a tertiary care hospital in Turkey. FEMS Microbiol Lett 282: 214218.

18. Mugnier PD, Poirel L, Nordmann P (2009) Functional Analysis of Insertion Sequence ISAbal, Responsible for Genomic Plasticity of Acinetobacter baumannii. J Bacteriol 191: 2414-2418.

19. Turton J F, Ward ME, Woodford N, Kaufmann ME, Pike R, Livermore DM, Pitt TL (2006) The role of ISAbal in expression of OXA carbapenemase genes in Acinetobacter baumannii. FEMS Microbiol Lett 258: 72-77.

20. Tripodi M-F, Durante-Mangoni E, Fortunato R, Utili R, Zarrilli R (2007) Comparative activities of colistin, rifampicin, imipenem, sulbactam/ampicillin alone or in combination against epidemic multidrug-resistant Acinetobacter baumannii isolates producing OXA-58 carbapenemases. Int J Antimicrob Agents 30: 537-540.

21. Mussi MA, Limansky AS, Viale AM (2005) Acquisition of resistance to carbapenems in multidrug-resistant clinical strains of Acinetobacter baumannii: natural insertional inactivation of a gene encoding a member of a novel family of $\beta$-barrel outer membrane proteins. Antimicrob Agents Chemother 49: 1432-1440.

22. Fernandez-Cuenca F, Martínez-Martínez L, Conejo MC, Ayala JA, Perea EJ, Pascual A (2003) Relationship between beta-lactamase production, outer membrane protein and penicillin-binding protein profiles on the activity of carbapenems against clinical isolates of Acinetobacter baumannii. J. Antimicrob Chemother 51: 565-574.

23. Heritier C, Poirel L, Lambert T, Nordmann P (2005) Contribution of acquired carbapenem-hydrolyzing oxacillinases to carbapenem resistance in Acinetobacter baumannii. Antimicrob Agents Chemother 49: 3198-3202.

24. Coelho JM, Turton JF, Kaufmann ME, Glover J, Woodford N, Warner M, Palepou MF, Pike R, Pitt TL, Patel BC, Livermore DM (2006) Occurrence of carbapenem-resistant Acinetobacter baumannii clones at multiple hospitals in London and Southeast England. J Clin Microbiol 44: 36233627.

25. van den Broek PJ, Arends J, Bernards AT, De Brauwer E, Mascini EM, van der Reijden TJ, Spanjaard L, Thewessen EA, van der Zee A, van Zeijl JH, Dijkshoorn L (2006) Epidemiology of multiple Acinetobacter outbreaks in The Netherlands during the period 1999-2001. Clin Microbiol Infect 12: 837-843.

26. Nemec A, Krizova L, Maixnerova M, Diancourt L, van der Reijden TJ, Brisse S, van den Broek P, Dijkshoorn L (2008) Emergence of carbapenem resistance in Acinetobacter baumannii in the Czech Republic is associated with the spread of multidrug resistant strains of European clone II. J Antimicrob Chemother 62: 484-489.

27. Da Silva GJ, Quintera S, Bertolo E, Sousa JC, Gallego L, Duarte A, Peixe L; Portugese Resistance Study Group 
(2004) Long-term dissemination of an OXA-40 carbapenemase-producing Acinetobacter baumannii clone in the Iberian Peninsula. J Antimicrob Chemother 54: 255258.

28. Wybo I, Blommaert L, De Beer T, Soetens O, De Regt J, Lacor P, Piérard D, Lauwers S (2007) Outbreak of multidrug-resistant Acinetobacter baumannii in a Belgian university hospital after transfer of patients from Greece. J Hosp Infect 67: 374-380.

29. Schulte B, Goerke C, Weyrich P, Gröbner S, Bahrs C, Wolz C, Autenrieth IB, Borgmann S (2005) Clonal spread of meropenem-resistant Acinetobacter baumannii strains in hospitals in the Mediterranean region and transmission to south-west Germany. J Hosp Infect 61: 356-7.

30. D'Arezzo S, Capone A, Petrosillo N, Visca P, on behalf of GRAB (2009) Epidemic multidrug-resistant Acinetobacter baumannii related to European clonal types I and II in Rome (Italy). Clin Microbiol Infect 15:347-357.

31. Stoeva T, Higgins PG, Savov E, Markovska R, Mitov I, Seifert H (2009) Nosocomial spread of OXA-23 and OXA58 beta-lactamase-producing Acinetobacter baumannii in a Bulgarian hospital J Antimicrob Chemother 63:618-620.

32. Marchaim D, Navon-Venezia S, Leavitt A, Chmelnitsky I, Schwaber MJ, Carmeli Y (2007) Molecular and epidemiologic study of polyclonal outbreaks of multidrugresistant Acinetobacter baumannii infection in an Israeli hospital. Infect Control Hosp Epidemiol 28: 945-950.

33. Giannouli M, Tomasone F, Agodi A, Vahaboglu H, Daoud Z, Triassi M, Tsakris A, Zarrilli R (2009) Molecular epidemiology of carbapenem-resistant Acinetobacter baumannii strains in intensive care units of multiple Mediterranean hospitals. J Antimicrob Chemother 63: 828830.

34. Mugnier P, Poirel L, Pitout M, Nordmann P (2008) Carbapenem-resistant and OXA-23-producing Acinetobacter baumannii isolates in the United Arab Emirates. Clin Microbiol Infect 14: 879-882.

35. Feizabadi MM et al. (2008) Antimicrobial susceptibility patterns and distribution of $b l a_{\mathrm{OXA}}$ genes among Acinetobacter spp. isolated from patients at Tehran hospitals. Jpn J Infect Dis 61: 274-278.

36. Villegas MV, Kattan JN, Correa A, Lolans K, Guzman AM, Woodford N, Livermore D, Quinn JP, and the Colombian Nosocomial Bacterial Resistance Study Group (2007) Dissemination of Acinetobacter baumannii clones with OXA-23 carbapenemase in Colombian hospitals. Antimicrob Agents Chemother 51: 2001-2004.

37. Merkier AK, Catalano M, Ramirez MS, Quiroga C, Orman B, Ratier L, Famiglietti A, Vay C, Di Martino A, Kaufman S, Centron D (2008) Polyclonal spread of blaOXA-23 and blaOXA-58 in Acinetobacter baumannii isolates from Argentina. J Infect Developing Countries 2: 235-240.

38. Marais E, de Jong G, Ferraz V, Maloba B, Dusé AG (2004) Interhospital transfer of pan-resistant Acinetobacter strains in Johannesburg, South Africa. Am J Infect Control 32: 278-281.

39. Poirel L, Mansour W, Bouallegue O, Nordmann P (2008) Carbapenem-resistant Acinetobacter baumannii isolates from Tunisia producing the OXA-58-like carbapenemhydrolyzing oxacillinase OXA-97. Antimicrob Agents Chemother 52: 1613-1617.

40. Hsueh P-R et al. (2002) Pandrug-resistant Acinetobacter baumannii causing nosocomial infections in a university hospital, Taiwan. Emerg Infect Dis 8: 827-832.
41. Mendes RE, Bell JM, Turnidge JD, Castanheira M, Jones RN. (2009) Emergence and widespread dissemination of OXA-23, -24/40 and -58 carbapenemases among Acinetobacter spp. in Asia-Pacific nations: report from the SENTRY surveillance program. J Antimicrob Chemother 63: 55-59.

42. Peleg AY, Bell JM, Hofmeyr A, Wiese P (2006) Intercountry transfer of Gram-negative organisms carrying the VIM-4 and OXA-58 carbapenem-hydrolysing enzymes. J Antimicrob Chemother 57: 794-795.

43. Naas T, Levy M, Hirschauer C, Marchandin H, Nordmann P (2005) Outbreak of carbapenem-resistant Acinetobacter baumannii producing the carbapenemase OXA-23 in a tertiary care hospital of Papeete, French Polynesia. J Clin Microbiol 43: 4826-4829.

44. Hujer KM, Hujer AM, Bajaksouzian S, Adams JM, Donskey CJ, Ecker DJ, Massire C, Eshoo MW, Sampath R, Thomson JM, Rather PN, Craft DW, Fishbain JT, Ewell AJ, Jacobs MR, Paterson DL, Bonomo RA (2006) Analysis of antibiotic resistance genes in multidrug-resistant Acinetobacter sp. isolates from military and civilian patients treated at the Walter Reed Army Medical Center. Antimicrob Agents Chemother 50: 4114-4123.

45. Hawley JS, Murray CK, Griffith ME, McElmeel ME, Fulcher LC, Hospenthal DR, Jorgensen JH (2007) Susceptibility of Acinetobacter strains isolated from deployed U.S. military personnel. Antimicrob Agents Chemother 51: 376-378.

46. Scott P, Deye G, Srinivasan A, Murray C, Moran K, Hulten E, Fishbain J, Craft D, Riddell S, Lindler L, Mancuso J, Milstrey E, Bautista CT, Patel J, Ewell A, Hamilton T, Gaddy C, Tenney M, Christofer G, Petersen K, Endy T, Petruccelli B (2007) An outbreak of multidrugresistant Acinetobacter baumannii-calcoaceticus complex infection in the US military health care system associated with military operations in Iraq. Clin Infect Dis 44:15771584 .

47. Motaouakkil S, Charra B, Hachimi A, Nejmi H, Benslama A, Elmdaghri N, Belabbes H, Benbachir M Colistin and rifampicin in the treatment of nosocomial infections from multiresistant Acinetobacter baumannii. (2006) J Infect 53:274-278.

48. Shankar P R, Upadhyay D K, Subish P, Dubey A K, Mishra P (2006) Prescribing patterns among paediatric inpatients in a teaching hospital in western Nepal. Singapore Med J 47: 261-265.

49. Iregbu KC, Ogunsola FT, Odugbemi TO (2002) Infections caused by Acinetobacter species and their susceptibility to 14 antibiotics in Lagos University Teaching Hospital, Lagos, West Afr J Med 21: 226-9.

50. Chawla R. (2008) Epidemiology, etiology, and diagnosis of hospital-acquired pneumonia and ventilator-associated pneumonia in Asian countries. Am J Infect Control 36:S93-100.

51. Towner KJ, Levi K, Vlassiadi M; ARPAC Steering Group (2008) Genetic diversity of carbapenem-resistant isolates of Acinetobacter baumannii in Europe. Clin Microbiol Infect 14: 161-7.

52. Lolans K, Rice TW, Munoz-Price LS, Quinn JP (2006) Multicity outbreak of carbapenem-resistant Acinetobacter baumannii isolates producing the carbapenemase OXA- 40 . Antimicrob Agents Chemother 50: 2941-2945.

53. Turton JF, Gabriel SN, Valderrey C, Kaufmann ME, Pitt TL (2007) Use of sequence-based typing and multiplex 
PCR to identify clonal lineages of outbreak strains of Acinetobacter baumannii. Clin Microbiol Infect 13: 807815.

\section{Corresponding Author}

Raffaele Zarrilli

Department of Preventive Medical Sciences, Hygiene Section

University of Naples 'Federico II'

Via Pansini nr. 5, 80131

Napoli, Italy

Email: rafzarri@unina.it

Conflict of interest: No conflict of interest is declared. 